\title{
An Efficiency Assessment of Lower Usuma Water Treatment Plant in Abuja Metropolis, Nigeria
}

\author{
Ibrahim A. Q ${ }^{1}$., Onyenekwe P. $C^{2} \&$ Nwaedozie I. $\mathrm{M}^{3}$ \\ ${ }^{1}$ Environmental Management Technology Programm, Abubakar Tafawa Balewa University-Bauchi-Nigeria \\ ${ }^{2}$ Shada Science Complex, Abuja, Nigeria \\ ${ }^{3}$ National Office for Technology Acquisition and Promotion (NOTAP), No 4 Blantyre Street, Wuse ii, Abuja, \\ Nigeria
}

\begin{abstract}
Treatment of public water supply is an essential service in both developed and developing countries.Maintaining optimal environmental health and minimising prevalence of waterborne diseases are among critical challenges to development particularly in Africa It is a pro-active approach in public water supply quality control management to ensure consumers safety. The Lower Usuma Water Treatment commenced supply portable water to Abuja Metropolis in 1987.In recent past, media reports were up that Abuja Metropolis may likely to experience widespread incidence of waterborne diseases if the current situation is not checked. Only $42 \%$ of Abuja residents had access to safe water source. This underscores the relevance of the study to access the efficiency of the Lower Usuma Water Treatment (LUWT) Plant to supply portable water to Abuja Metropolis . Physico-chemical and bacteriological parameters of both the raw and treated water were stratifically sampled, and analyzed according to Standard Methods and Procedures. The results indicated that the source water was moderately contaminated.Plant Log Removal Value(LRV) and Efficiency were as follows: Physical parameters $(0.48$ to 0.51) and efficiency (65.25 to 68.19\%),Chemical parameters (0.29-0.44 and efficiency(32.74-49.72\%), heavy Heavy metals (0.25-0.52) \& efficiency(63.2863.57\%); Bacteriological parameters (0.69-1.28), and efficiency (59.93-67.87\%). The Overall average LRV and percentage efficiency of the LUWT were found to be 0.56 and $64 \%$ respectively within the period of study. The quality of treated water was found to be significantly in compliance with the WHO Guideline Values for safe drinking water but it runs short of public demand due to development in the Metropolis. The study recommended that the plant unit operation should be scaled up and re-engineered to improve its efficiency and therefore minimise the frequency/incidence of waterborne diseases in the Abuja Metropolis. The study concluded that the LUWT plant was still technologically appropriate to deliver safe water to the public within the period under study.
\end{abstract}

Key words: Efficiency, Assessment, Lower Usuma Treatment Plant, Abuja Metropolis,

\section{Introduction}

Water is one of the most important elements for all forms of life. It is indispensable in the maintenance of life on earth. Poor access to safe water sources (pipe borne and borehole) in both urban and rural areas have been implicated for the prevalence of water diseases in Nigeria. Provision of safe water to the people has become a common promise amongst politicians during political campaign in Nigeria. The World Health organisation estimated that up $80 \%$ of all sickness in the world are caused by inadequate sanitation, polluted water or unavailability of safe water(1).The majority of the population in developing countries are not adequately supplied with potable water and are thereby compelled to use water from doubtful sources(2).

The World Health Organization says that every year more than 3.4 million people die as a result of water related diseases, making it the leading cause of disease and death around the world. Most of the victims are young children, the vast majority of whom die of illnesses caused by organisms that thrive in water sources contaminated by raw sewage. A report published recently in the medical journal The Lancet concluded that poor water sanitation and a lack of safe drinking water take a greater human toll than war, terrorism and weapons of mass destruction combined. According to an assessment commissioned by the United Nations, 4,000 children die each day as a result of diseases caused by ingestion of filthy water. The report says four out of every 10 people in the world, particularly those in Africa and Asia, do not have clean water to drink.

Water is essential for all socio-economic development and for maintaining healthy ecosystems. As population increases and development calls for increased allocations of ground water and surface water for domestic, agriculture and industrial sectors, the pressure on water resources intensifies, leading to tensions, conflicts among users, and excessive pressure on the environment. The increasing stress on freshwater resources brought about by ever - rising demand and profligate use, as well as by growing pollution worldwide, is of serious concern. 
In Nigeria, and particularly in its Federal Capital Territory (FCT)-Abuja, key sources drinking water varies from public pipe borne to boreholes, rivers/lakes and open hand dug wells. The geometrical growth of population in Abuja Metropolis has created enormous challenges on the natural resources such as water supply and the only source of public pipe borne water supply is from Lower Usuma Treatment Plant(LUTP) commissioned in 1987 by the Federal Government of Nigeria- to ensure portable water supply to the emerging new capital city. The inadequacy of public pipe borne water supply in Abuja metropolis necessitated the scaling up of the Lower Usuma Water Treatment Plant from its original capacity of $5,000 \mathrm{~m}^{3}$ per hour to its present capacity of $10,000 \mathrm{~m}^{3}$ in 1992 .

It is pertinent to note that the Lower Usuma Treatment Plant was Turn-key project agreement between Nigerian Government and a Japanese Company in early 80's but since the commencement of the operation, there is clear dearth information on the efficiency of the plant, at least to ascertain that it delivers safe water to the public and this single reason underscores the relevance of this study

Water utilities select a combination of treatment processes most appropriate to treat the contaminants found in the raw water used by the system. Some include flocculation/ sedimentation, filtration, ion exchange, absorption and disinfection

The major water quality problems being faced currently is the upwards trend in the prevalence of water borne diseases in the metropolis. The metropolis has various sources of drinking water supply which include rivers \& lakes, open wells, hand dug wells, pipe bore water, boreholes etc.

The type of treatment applied by a public water system varies with the source type and quality. Many ground water systems can satisfactorily, all federal requirements without applying any treatment, while others need to add chlorine or additional treatment(3). The Lower Usuma Water treatment plant treats the raw water from the nearby open surface earth reservoir .Through its init operation, it ensures that dangerous microscopic pathogens are inactivated along the 73.770 kilometer water distribution in Abuja Metropolis.

Plant efficiency is measured as the ratio of some quality output to input. The present trend to monitor the treatment plants is on the basis of Log Removal Efficiency of the parametric values of input and output of the treatment system.. For example, the biochemical Oxygen demand (BOD) removal efficiency of treatment plant is $75 \%$ or Chemical oxygen demand (COD) removal efficiency is $68 \%$ and so on. This is fair and acceptable when dealing with parametric removal studies. However, the parametric values are not individually separated out when discharges are released into the receiving bodies. Also, the parameters do have interrelationship with one another and so cannot be viewed independently in terms of plant efficiency(4).

In this study, the Log Removal Efficiency of LUTP was determined from the input and output analysis of the plant. Critical physical, chemical and bacteriological parameters were selected. These include; Since PH, turbidity, residual chlorine, thermo-tolerant coli forms and Escherichia coli forms have been considered as the most standard parameters for the performance assessment of the treatment plant $(5,6)$, therefore attention would be paid to these water quality parameters while conducting this study.

The regular monitoring of water quality being treated by water purification systems and the performance assessment of its unit operations and processes is very essential for public health safety.

The primary purpose of water treatment is to provide water to consumers that are free of waterborne pathogens. Because no single treatment process can be expected to remove all of the different types of pathogens that can be found in water, multiple barriers are desirable. Multiple barriers will also ensure additional safety in a case of that a single treatment system is not working optimally. The number of treatment processes required is influenced by the quality of the source water. Groundwaters that are protected from the surface influence are usually of relatively good quality and so traditionally few, if any treatment processes are required. Lowland surface water sources are usually of much poorer quality and more treatment processes are needed to provide an acceptable level of safety (7)

A wide spectrum of pathogens can be found in water and monitoring for their presence on a routine basis is impracticable. Traditionally microbial safety of drinking water has been confirmed by monitoring for the absence of microorganisms of faecal origin and bacteria such as E. Coli, Faecal streptococci and Clostridia have been used for this purpose because they are consistently present in high numbers in the faeces of warm blooded animals and are relatively easy to detect in water. These bacteria and groups of bacteria are microbial indices of faecal pollution and form the basis of guidelines and national standards (7)

\section{1: The study Plant:}

\section{Materials and Method}

The Lower Usuma Water Treatment Plant (LUWTP) is located within the Lower Usuma Water Works in Bwari Area Council at the periphery of Abuja Metropolis. It lies between the Latitude of $8^{0} 25$ and $9^{0} 25 \mathrm{~N}$ and Longitude $6^{0} 45$ and $7^{0} 45 \mathrm{E}$ with an elevation of 2,000 meters above the sea level. Located at a higher altitude and therefore delivers portable to Abuja Metropolis by gravity, see figure 1. The plant was constructed in 1987 and since then it has been the main source of drinking water for the city of Nigeria and its environs. 


\section{2 the Treatment Plant:}

The water treatment technology involves aeration followed by removal of large solids implementing drum screens. The water then passes through the lamella sludge blanket clarifier / inclined-plate clarifier in place of conventional settling tanks for clarification. The technology makes use of highly compact settlers, reducing the space requirements compared with the latter by up to $90 \%$. This clarified water is put to rapid gravity filtration by passing it through a filter medium consisting of sand filters, by gravity or under pumped pressure. The filter removes flocculated materials trapped in the sand. Then the water is disinfected in the contact tank with chlorine and goes through chemical dosing using aluminium sulphate, lime, polyelectrolyte and chlorine. Sand filters are cleaned by backwashing, which involves reversing the direction of the water and adding compressed air.

Figure1: Lower Usuma Water Treatment Plant Plant

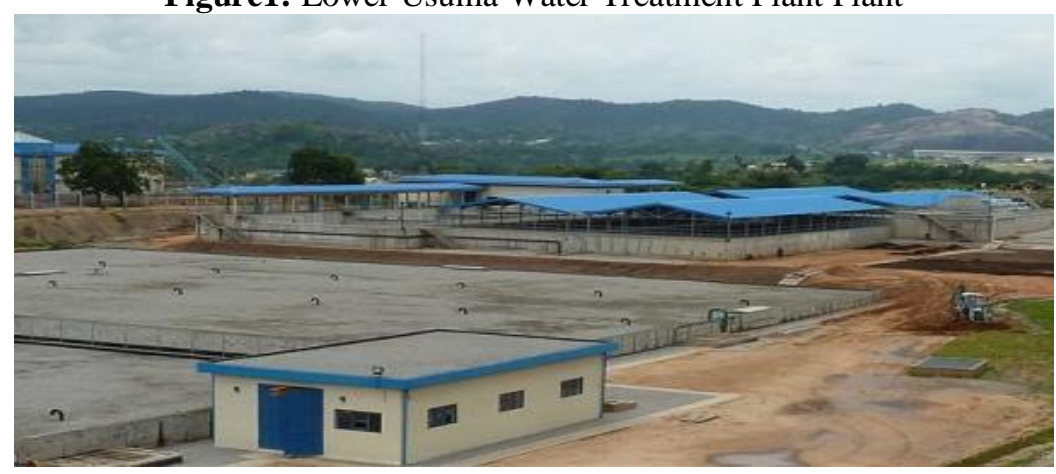

\section{3: Sampling Techniques:}

A stratified sample techniques was adopted. Samples of the treated and untreated water supplies were taken from the designated taps located within the water works. Water samples were taken in the morning period in January, March, May, July, September and November covering both the dry and rain seasons for two consecutive years. Samples were taken three times in each month from which the monthly mean was calculated and recorded. All samplings were taken according to the Standard Methods and Procedures..

\section{4: Scope of the study:}

The scope of the study was to assess the efficiency of the Lower Usuma Water treatment Plant between 2009 to 2010 with the primary objective to justify that the treatment plant actually delivers safe water to the public as designed

\section{5: Laboratory Methods}

Colour was determined with a DR-5000 HACH Meter and recorded in Pt.Co unit as shown in table 1.

The Hydrogen ion concentration $\left(\mathrm{P}^{\mathrm{H}}\right)$ was determined with a $\mathrm{PH}-$ Meter (Eo Terr model . The instrument was calibrated using bromothymol blue solution of 32G/l of alcohol as buffer solution. The calibrated meter was dipped into the water sample and the reading was recorded.

Turbidity was measured with a Turbidity Meter (HANNA-LP 2000-!!) The curvet was cleaned with serviette to allow free light absorption. The curvet in the instrument was filled with water sample and the instrument switched on, the reading was recorded.

The residual chlorine was determined with the aid of Chlorine Colorimeter (HACH - Test kit, Cat No. 58700-00) after due calibration according to Standard procedures (120 pragramme and 450 wavelength) using appropriate pillows.

Thermo-tolerant and Escherichia coli forms were determine by Membrane Filtration Method using MEdo at $37^{\circ} \mathrm{C}$ and MFC Agar at $44^{\circ} \mathrm{C}$ for presumptive and confirmatory test respectively. All the laboratory analysis were carried out according to Standard Methods and Procedures.

\section{5: Statistical Analysis:}

Micro soft Excel software Analyze ${ }^{\text {it }}$ was deployed to determine quality variations over time and seasons as well as the compliance with the WHO guideline values for drinking water. The overall efficiency of the plant was determined using Log Removal Value mathematical formula. 


\section{Results and Discussions}

In order to assess the water treatment plant efficiency, a physico--chemical and bacteriological analysis were carried out between 2009 to 2010. The aim was to use input -output method to assess the efficiency of the treatment processt. The results are presented in table 1 while its relationship with the WHO Guideline limits for safe drinking water are shown in chats 1-7 below. The overall efficiency of the plant was calculated using the Log Removal value (LRV) and overall parametric efficiencies equation. The results are presented in table 2.

Colour in drinking water may be due the presence of coloured organic matter particularly in a tropical surface water bodies e.g. humic substances, metals such as iron or manganese, or highly coloured industrial wastes(8).Changes in colour from that normally seen can provide warning of possible quality changes due to maintenance issues and should be investigated. They may be .for example, reflect degradation at the source water, corrosion problems in distribution systems, changes in performance of adsorptive treatment processes such as activation carbon filtration. In general, color is reduced or removed from water through the use of coagulation, settling and filtration techniques. Aluminum sulfate is the most widely used coagulant for this purpose. Super chlorination, activated carbon filters and potassium permanganate have been used with varying degrees of success in removing color(8). Chat 1 clearly shows that the source water for the treatment plant was off- WHO recommendation and with the intervention of the treatment processes, the water colour quality was optimized.

Generally, the $\mathrm{pH}$ of both the raw and the treated water was found to be below 7 neutral points throughout the study period. The implication of this is that the efficiency of chlorination would be enhanced in the protection of water against pathogenic contaminants but it would also stimulate corrosion of metallic components of the distribution facilities, and may lead to equipment failure.PH is associated with corrosion, hardness, acidity chlorination, coagulation and Alkalinity(9). The plant efficiency of optimizing $\mathrm{pH}$ was found to be $1.56 \%$ indication that the treatment process had no significant change on the $\mathrm{P}^{\mathrm{H}}$ of the raw water. The acidity of the raw water has been highlighted notable scholars which include $(10,11,12,13 \& 14)$. The relation with the WHO Guideline limit is shown in chat 2 below.

Turbidity is a measure of suspended solids. It is a very critical water quality because it is probably the most general applicable and widely used non-microbial parameter that can provide the most the significant data throughout out the water abstraction and treatment process(8). It is associated specifically with facial materials, but increases in turbidity are often accompanied with increase in pathogen numbers cysts or oocysts. Turbidity of water affects treatment processes and especially disinfection with chlorine -bases chemicals. It is important to know that turbidity characteristics of water sources and to respond to unexplained changes turbidity. Turbidity of surface water sources may be heavily influences by rainfall events or algal growth and treatment processes should be tailored to respond to such change(8). The turbidity of public water from the Lower Usu

Refma Water Treatment Plant was found to be within the WHO standard of 5NTU, see chat 3. Turbidity of treated drinking water has been linked to health effects in Milwaukee, $(15,16,17)$. It should be noted , however, that these studies of turbidity and adverse health outcome are "ecological", in that they measure exposure of populations rather than of individuals and, as such, potentially suffer from bias due to the so called ecological "fallacy(18). While this does not proof of an association in their own rights(8).

According Karen Garvin of WOCKHART HOSPITALS, India in 2014 said "The thing that you'll notice the most from water that is high in iron is that the water may taste metallic. The water may be discolored and appear brownish, and it may even contain sediment. Iron will leave red or orange rust stains in the sink, toilet and bathtub or shower. It can build up in your dishwasher and discolor ceramic dishes. It can also enter into the water heater and can get into the laundry equipment and cause stains on clothing. The EPA cautions that although iron in drinking water is safe to ingest, the iron sediments may contain trace impurities or harbor bacteria that can be harmful. It is possible for you to get too much iron through your diet, but ingesting too much iron through your drinking water is not associated with adverse health effects"

In drinking-water supplies, iron (II) salts are unstable and are precipitated as insoluble iron(III)hydroxide, which settles out as a rust-coloured silt. Anaerobic groundwaters may contain iron (II) at concentrations of up to several milligrams per litre without discoloration or turbidity in the water when directly pumped from a well, although turbidity and colour may develop in piped systems at iron levels above $0.05-0.1$ $\mathrm{mg} /$ litre. Staining of laundry and plumbing may occur at concentrations above $0.3 \mathrm{mg} / \mathrm{litre}(21)$.

Total coliform organisms, better referred to as total coli forms to avoid confusion with others in the group, are not an index of faecal pollution or of health risks, but can provide basic information on source water quality. Total coliforms have long been utilized as a microbial measure of drinking water quality, largely because they are easy to detect and enumerate(8).The most common and widespread of health risk associated with drinking water is contamination, either directly or indirectly, by human or animal excreta, particularly faeces. If such contamination is recent, and if those responsible for it include carriers of communicable enteric 
disease, some of the pathogenic microorganisms that cause these diseases may be present in water. Drinking the water or using it for food preparation may then result in new cases of infection (8).

The total Coliform organisms were observed to be present in the source water in both seasons of 2009 and 2010. It ranged from the mean $9.75 \pm 0.29$ to $9.30 \pm 3.06$ in 2010 respectively as against the WHO recommended limit of $10 \mathrm{CFU} / 100 \mathrm{ml}$. This in effect justifies the treatment energy and materials expended in the treatment processes of the source water, see table 1, and chat 4. Similar contemporary scholarly works in this area of study is limited developing countries and sub-Sahara Africa imparticular,only but few such as (4 ,19).

The Log Removal Value of the E. coli forms found to be 0.52 with an overall efficiency of $63.28 \%$. While that of the E. Coli forms were found to 1.28 with an overall efficiency of $93.21 \%$, E.coli forms were never found in the treated water meant for supply to the public within the period under study, see chat 6 \& 7 .

The presence of free chlorine residual in drinking water indicated that a sufficient amount of chlorine was added to the water to inactivate most of the bacteria and viruses that cause diarrheal diseases and that water is protected from recontamination during transport to the home, and during storage and handling of water in the household. Because of the presence of free chlorine residual in drinking water indicated absence of diseases -causing organism, it is used as one measure of the portability of drinking water, (20).

The optimization of free chlorine residual of the Lower Usuma Treatment plant was found to be 0.67 with an overall mean efficiency of $79.00 \%$ within the study period. Iron $\left(\mathrm{Fe}^{2+}\right) \log$ value and overall mean efficiency was found to be 0.44 and $84.00 \%$ respectively, see table 1 above.

Table 1: Mean physicochemical Characteristics of Raw and Treated Water Supplies to the Lower Usuma Water Treatment Works, Abuja, Nigeria

$\begin{array}{llllll}\text { Parameters } & 2009 & & 2010 & & \text { WHO STD. } \\ & \text { Raw } & \text { Treated } & \text { Raw } & \text { Treated } & \\ \text { Colour } & 15.99 \pm 3.49 & 7.88 \pm 0.48 & 30.25 \pm 1.32 & 8.17 \pm 0.57 & 15 \mathrm{Pt} . \mathrm{C} 0 \\ \text { PH } & 6.98 \pm 0.16 & 6.91 \pm 0.15 & 6.91 \pm 0.17 & 6.99 \pm 0.18 & 6.5-8.5 \\ \text { Turbidity } & 6.72 \pm 0.77 & 2.11 \pm 0.48 & 5.93 \pm 0.45 & 1.35 \pm 0.45 & 5 \mathrm{NTU} \\ \text { Residual Chlorine } & 0 \pm 00 & 0.22 \pm 0.04 & 0 \pm 00 & 0.2 \pm 0.02 & 0.20 \mathrm{mg} \mathrm{l}^{-1} \\ \text { Iron(fe }{ }^{2+)} & 0.27 \pm 0.04 & 0.12 \pm 0.02 & 0.27 \pm 0.04 & 0.29 \pm 0.09 & 0.30 \mathrm{mgl}^{-1} \\ \text { Total Coliforms } & 9.75 \pm 0.29 & 0.00 \pm 0.00 & 9.30 \pm 3.06 & 0 \pm 0.00 & 10.00 \mathrm{cfu} / 100 \mathrm{ml} \\ \text { Feacal Coliforms } & 2.34 \pm 1.5 & 0.00 & 2.23 \pm 0.45 & 0.00 & 0.00 \mathrm{cfu} / 100 \mathrm{ml}\end{array}$

Table 2: Seasonal overall Efficiency of the Lower Usman Treatment Plant for selected physico-

$\begin{array}{lcc} & \begin{array}{c}\text { chemical and bacteriological parameters (2009) } \\ \text { Parameters }\end{array} & \begin{array}{c}\text { Efficiency }(\%) \\ \text { Colour }\end{array} \\ \text { Turbidity } & 0.44 & 62.00 \\ \text { PH } & 0.52 & 69.00 \\ \text { R. Chlorine } & 6.5 \times 1.0-3 & 1.56 \\ \text { Iron(Fe2+) } & 0.67 & 79.00 \\ \text { Total Coli forms }(\mathrm{cfu} / 100 \mathrm{ml}) & 0.44 & 84.00 \\ \text { E. Coli forms(cfu/100ml) } & 0.52 & 63.28\end{array}$

Chat 1: Colour quality characteristics of Raw and Treated Lower Usuma Water, Abua, Nigeria(2009-2010)

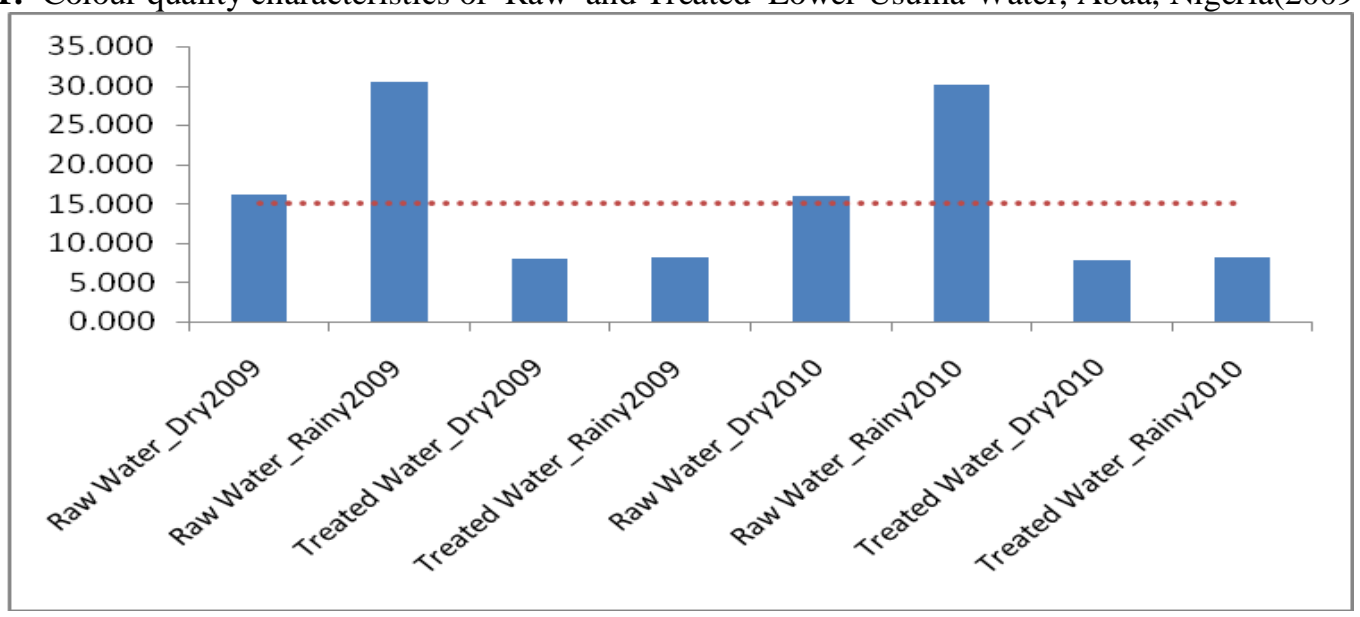


Chat 2: Turbidity quality characteristics of Raw and Treated Lower Usuma Water, Abuja, Nigeria(20092010)

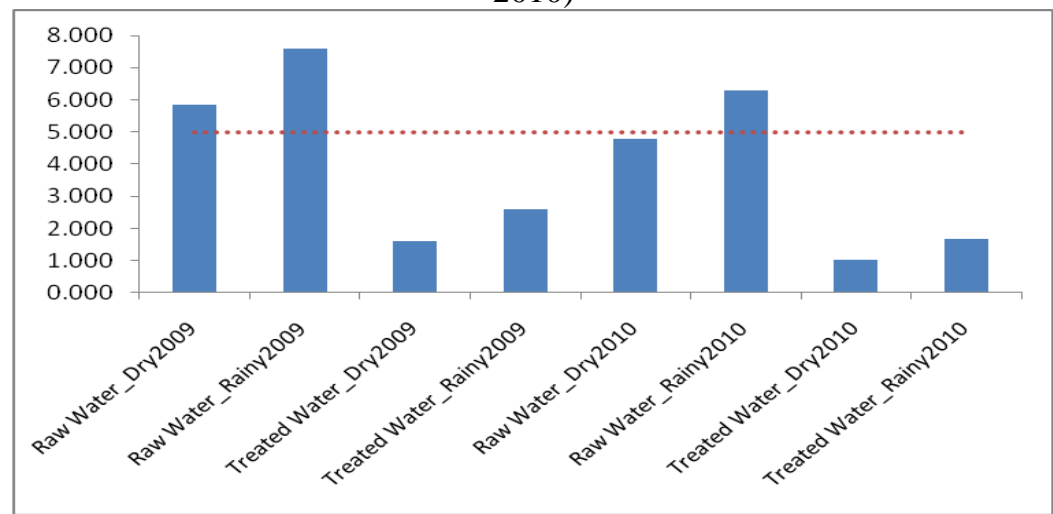

Chat 3: PH quality characteristics of Raw and Treated Lower Usuma Water, Abuja, Nigeria (2009-2010).

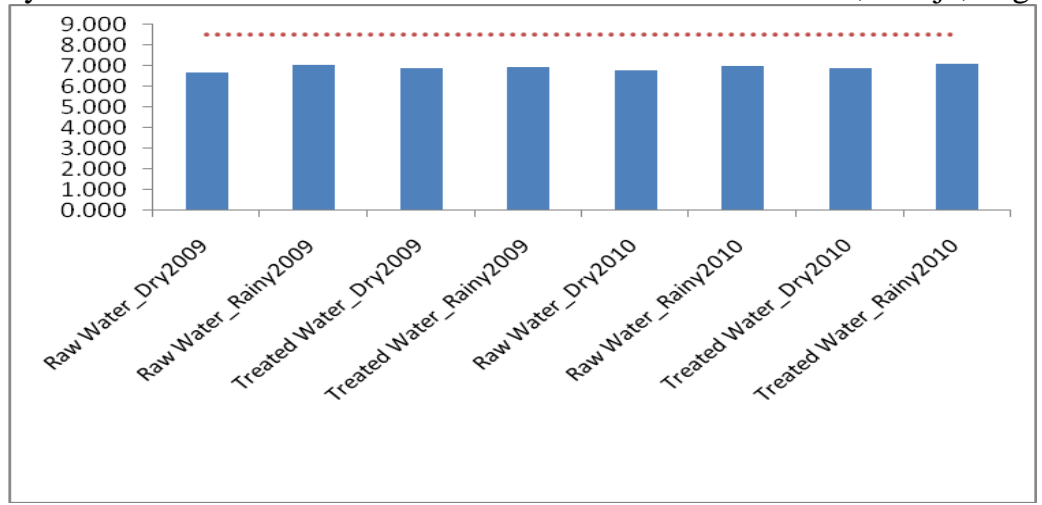

Chat 4: Residual Chlorine quality characteristics of Raw and Treated Lower Usuma Water,Abuja, Nigeria(2009-2010)

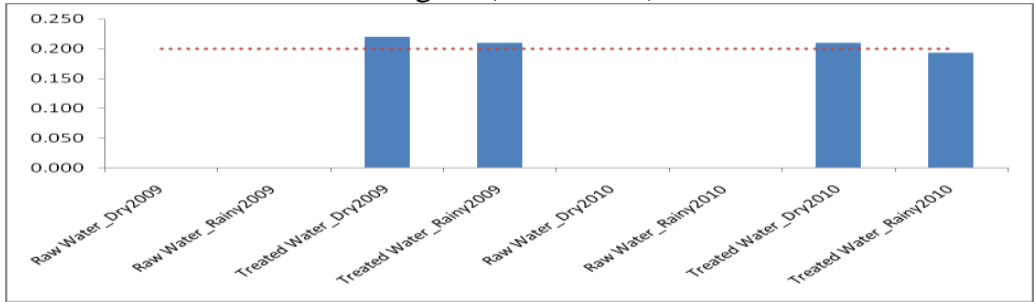

Chat 5: Iron $\left(\mathrm{Fe}^{2+}\right)$ quality characteristics of Raw and Treated Lower Usuma Water, Abuja,

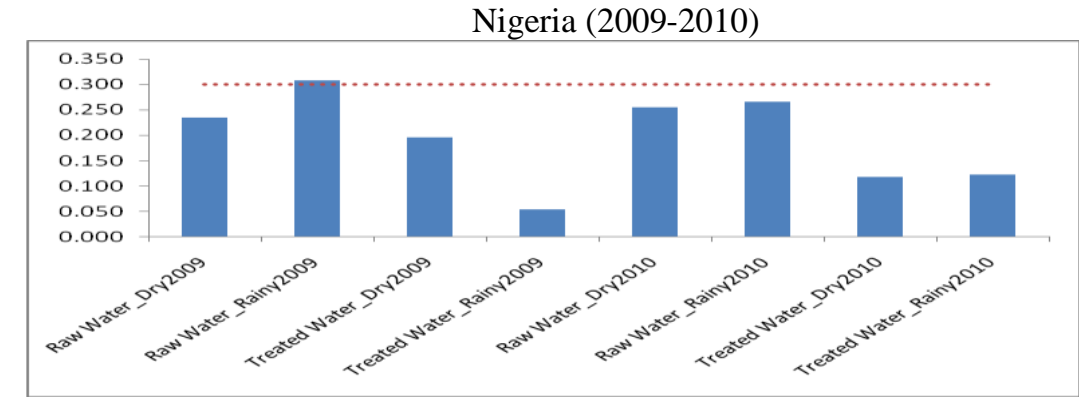

Chat 6: Total Coli forms quality characteristics of Raw and Treated Lower Usuma Water, Abuja, Nigeria(2009-2010) 


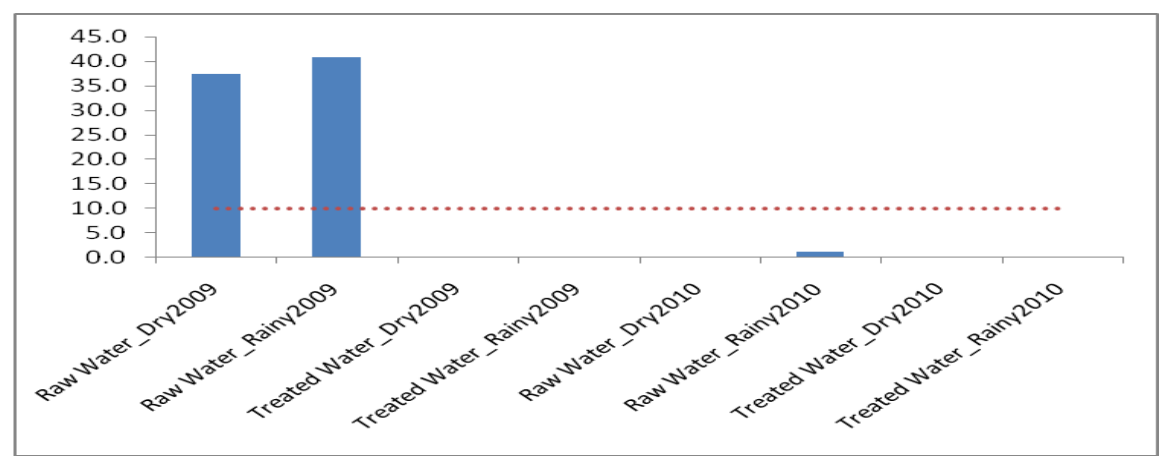

Chat 7: E. Coliforms quality characteristics of Raw and Treated Lower Usuma Water, Abuja, Nigeria (2009-2010)

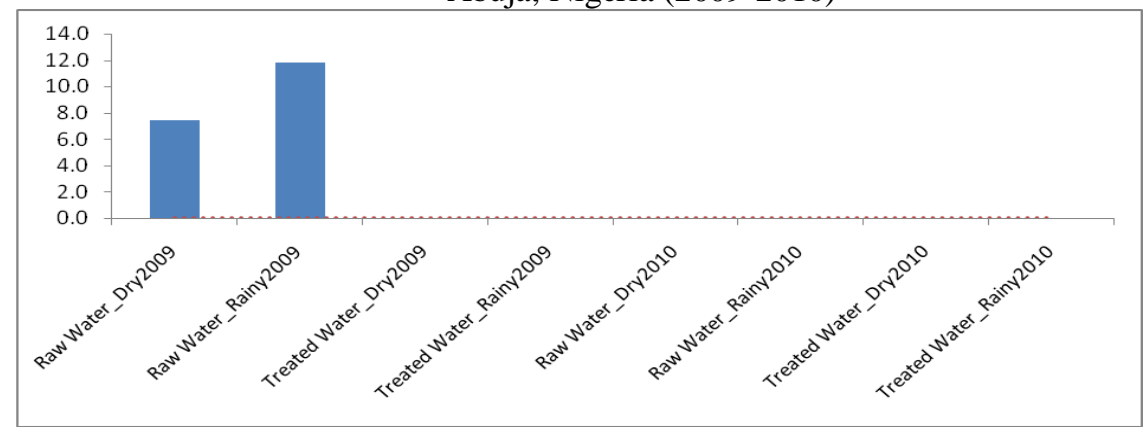

Safe drinking water is the result of careful evaluation of some source water quality and variation and combined adequate, reliable treatment processes combined with performance monitoring to assure that treatment is within the operating parameters and verification at the end of the treatment chain is necessary. A review of the available data on treatment efficiency has been published by (21) amongst others. Disinfection can be achieved in two ways: The physical removal of the pathogens and the inactivation of the pathogens (7)

The research found that the Lower Usuma Water treatment plant was efficiency enough to treat and deliver safe water to the public with an overall average efficiency of $62 \%$ (colour), 69\%(turbidity), $1.56 \%$ $(\mathrm{PH}), 79 \%$ (Chlorine Residual), $84 \%$ (Iron- $\mathrm{Fe}^{2+}$ ), $63.28 \%$ and $93.21 \%$ total and E. Coli respectively. The study recommended that the surrounding forest of the source water may be decleared a "Protected Zone" to minimize human activities around the water catchment zone which contributes to source water contamination. The LUWTP should also be re-engineered in order to improve its purification efficiency to ensure that it delivers safe water to the public. The study concluded that the water treatment technology deployed at the Lower Usuma Water treatment plant was appropriate to deliver safe water to the public within the study period.

\section{References}

[1]. WHO (1997): Guidelines for Drinking Water Quality, Second Edition Volume 3: Surveillance and Control of Community Supplies

[2]. WHO (2006): Guidelines for Drinking - water Quality. First addendum to Third Edition. Vol. 1 Recommendations

[3]. United State Environmental Protection Agency: Drinking Water Treatment Safe Drinking Water Act(1974-2004).Protect Our Health from Source to Tap:

[4]. Kamhambete A. K. ,R.A. Christian(2011): Evaluting Overall Efficiency of Sewage Treatment plant Using Fuzzy Composition. World Applied Science journal 12:293-298

[5]. Wodood R.(2001): bacteriological analysis of drinking water supplied to Faisalabad and evaluation of water purifiers-M.Sc. Thesis ,Faculty of Veterinary Sciences, University of Agriculture ,Faisalabad, Pakistan

[6]. Collivignarelli C. et all (2008): Evaluation of Drinking water treatment and qualityn in Tukua Pa,Thailand.Environmental Monitoring Assessment 142:345

[7]. Stanfield G.Lechevallier M. and Snozzi M.(2003): Treatment Efficiency: in Assessing Microbial Safety of Drinking Water .Improving Approaches and Methods,159-175.

[8]. OECD-WHO/DOC/WISH (2003): Assessing Microbial Safety of Drinking Water -Improving Approaches and Methods

[9]. Frank R.S. and Joanne D(2000): The Drinking water habdbook. Technomic publishing,Inc851 New Holland Avenue.B ox 3535, Lancaster, Pennsylvania 17604 USA,79-107

[10]. Egwu,A.I., Wakama, R.J., Kana, M.Z., La'ah, E. and Olotu, A.(2012): River Usuma: A Medium of Assessing Bioavailabity of Heavy Metals in Abuja.International Journal of Physical Sciences Vol.7(43),pp 597-5807

[11]. Ugwu ,A. I. and Wakawa R.J(2012): A study of Seasonal physico-chemical parameters in River Usman.A merican Journal of Environmental Science, 8(5) 569-576

[12]. Ojutiku, R. O.,Kolo ,R.J. and Mananaso ,C. A.(2014): Composition and Dynamics of Some Nutrient and Physico0chemical Parameters in Lower Course of Gwagwalada River in Federal Capital Territory, Abuja, Nigeria. American Journal of Agriculture,4(12),pp1480-1491

[13]. Dan-Kishiya,A.S., Olatunde, A. A. and Balogun ,J. K.(2012): Fish Species Distribution in a Domestic Water Supply Reservoire: A case Study of Lower Usuma Reservoire, Bwari Nigeria. Reasercher, 4(2) pp 56-60. 
[14]. Dan-Kishiya,A.S., Olatunde , A. A. and Balogun ,J. K.(2013):Variation of the Concentration of Dissolved Oxygen(DO) and Hydrogen ion Concentration at the Surface of a tropical Reservoire : A case study of Lower Usuma Reservoire in Bwari , Abuja , Nigeria. American Journal of Research Communication, pp204-214.

[15]. MacKenzie,W.R.,Hoxie,N.J.,Proctor, M. E., Gradus,M.S., Blair,K.., Rose ,J.B and Davis ,J.P.(1994): A massive outbreak in Mulwaukee of Cryptosoridium infection transmitted through the public water supply. Nwe England Journal of Medicine 331(3), 161-167

[16]. Morris, R.D and Levine,R.(1995):Esimating the incidence of waterborne infectious diseases related to drinking water in the United States. In: Assessing and Managing Health Risks fromDrinking Water Contamination: Approaches and Applications. Reichard, E. G., Zapponie, G. A.(Eds) IAHS Press, Wallingford, Oxfordshire, United Kingdom,pp 75-88

[17]. Bardeau , B. , payment,P., Coallier,J., Clement ,B. and provost, M.(2001): Evaluationg the risk of inection from the presence of Giardia and Cryptosporidium indrinking water.Wuantitative Microbiology 2, 37-5

[18]. Walter,S.(1991):The ecological method in the study of environmentaln health II. Methodologic issues and feasibility .Environmental Health Perspective 94,67-73

[19]. Arshad A., Hashim, N. H., Naseem, B., Shahid, I. and Khurram, M. (2012):Performance Evaluation of the Water plants of Isalamabad-Pakistan: Architectural Environmental Science 6,111-117

[20]. Centre for Disease Control and Prevention (CDC)-Safe Water System (SWS) Project: Chlorine Residual Testing Facts Sheet.1600 Clifton Rd. Atlanta,GA 30333,USA 800-CDC-INFO(800-232-4636) .Chlorine Residual Testing Fact Sheet, CDC SWS Project,safewater@cdc.gov

[21]. Department of National Health and Welfare (Canada).Nutrition recommendations. The report of the Scientific Review Committee. Ottawa, 1990.

[22]. LeChevallier,M. W. and AU. ,K.K.(2002):Water Treatment for Microbial Control :A Review Document .World Health Organization 